\title{
Computer Modelling For 4-Stroke Direct Injection Diesel Engine
}

\author{
Abdul Rahim Ismail, Rosli Abu Bakar, Semin \& Ismail Ali \\ Faculty of Mechanical Engineering, \\ Universiti Malaysia Pahang, \\ P.O. Box 12, 25000 Kuantan, Pahang. \\ abrahim@ump.edu.my
}

Keywords: GT-power, computational modeling, 4-stroke DI diesel engine.

\begin{abstract}
Study on computational modeling of 4-stroke single cylinder direct injection diesel engine is presented. The engine with known specification is being modeled using one dimension CFD GT-Power software. The operational parameters of the engine such as power, torque, specific fuel consumption and mean effective pressure which are dependent to engine speed are being discussed. The results from the simulation study are compared with the theoretical results to get the true trend of the results.
\end{abstract}

\section{Introduction}

Computer modelling in solving fluid dynamic problem in engineering is rapidly grown. The 1DCFD engine simulation tools commonly used in the entire engine development (e.g., GT-Power, Wave, PROMO, Boost) compute the flow field in internal combustion engines based on onedimensional fluid dynamics, thus representing the flow and the heat transfer in the piping and the other components of an engine system [1]. These tools can resolve flow effects only in the main direction (the pipe axis). They assume uniformity of the flow field in each perpendicular plane.

A study of computational method to simulate a four stroke single cylinder direct injection diesel engine has been performed using one dimension CFD GT-Power software. In this research, the engine performance parameters such as power, torque, specific fuel consumption and mean effective pressure are studied.

\section{Power}

The engine power is divided into two types; gross and net power. The gross power is from an engine without the cooling fan, muffler and tail pipe; whereas the net power is from the complete engine. The energy through the engine is expressed in three distinct terms; $i p, f p$ and $b p$. The $i p$ can be measured from the measurement of forces in the cylinder and $b p$ can be computed from the measurement of forces at the crankshaft of the engine. The difference between the $i p$ and the $b p$ of an engine is known as $f p$. It is shown in Eq. 1.

$$
f p=i p-b p
$$

Power is defined as the rate of doing work [4]. This may be converted to power by multiplying by the mass flow rate of air through the engine in $\mathrm{kg}$ per unit time. The net work obtained from the $\mathrm{p}-\mathrm{V}$ diagram is the net work produced in the cylinder as measured by an indicator diagram, the power based on there is shown in Eq. 2.

$$
\text { ip }=\dot{m}_{a} \times \text { net work of cycle }
$$




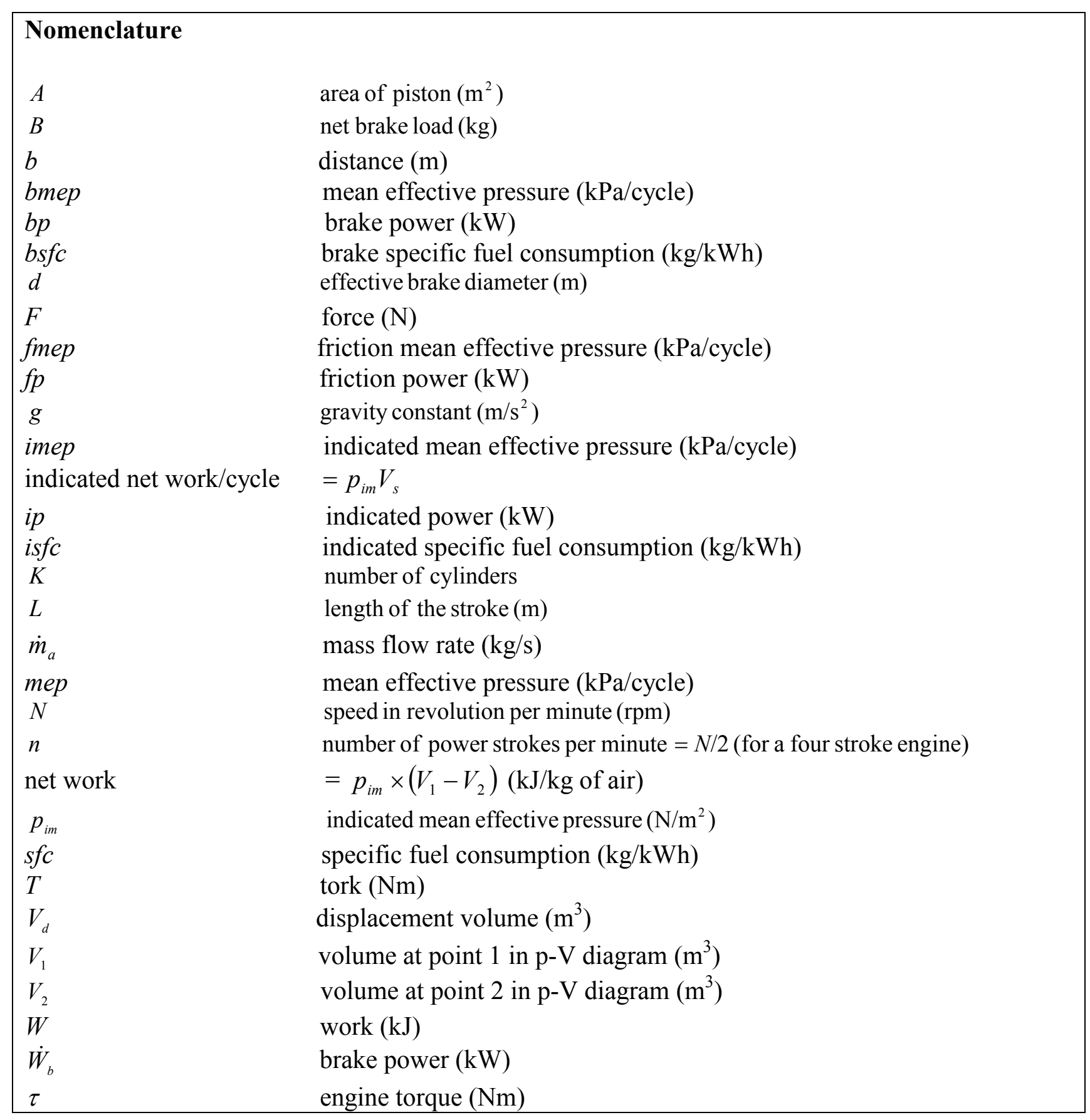

In working with actual engines, it is often desirable to compute ip from a given $p_{i m}$ and given engine operating conditions as shown in Eq. 3.

$$
\begin{aligned}
i p & =\frac{p_{i m} V_{s} n K}{1000 \times 60} \\
& =\frac{p_{i m} L A n K}{60000}
\end{aligned}
$$

The ip is based on indicated net work and is thus a measurement of the forces developed within the cylinder. More practical interest is the rotational force available at the delivery point, at the engine crankshaft, and the power corresponding to it. This power is called $b p$. This power can be measured by attaching a power absorption device to the drive-shaft of the engine [4]. Meanwhile the $b p$ is given by Eq. 4; 


$$
\begin{aligned}
b p & =\frac{W \pi N d}{60000} \\
& =\frac{B g N d}{60000}
\end{aligned}
$$

\section{Torque}

Torque is a measurement of an engine's ability to do work. Normally it is measured with a dynamometer. The rotor is coupled electromagnetically, hydraulically or by mechanical friction to a stator which is supported in low friction bearings. The stator is balanced with the rotor stationary. The torque exerted on the stator with the rotor turning is measured by balancing the stator with weights, springs or pneumatic means [3]. Using the notation in Figure 1, the torque exerted by the engine is shown in Eq. 5. The power delivered by the engine and absorbed by dynamometer is the product of torque and angular speed, as shown in Eq. 6. It can be simplified as in Eq. 7.

$$
\begin{aligned}
& T=F b \\
& P=2 \pi N T \\
& T=\frac{P \times 60000}{2 \pi N}
\end{aligned}
$$

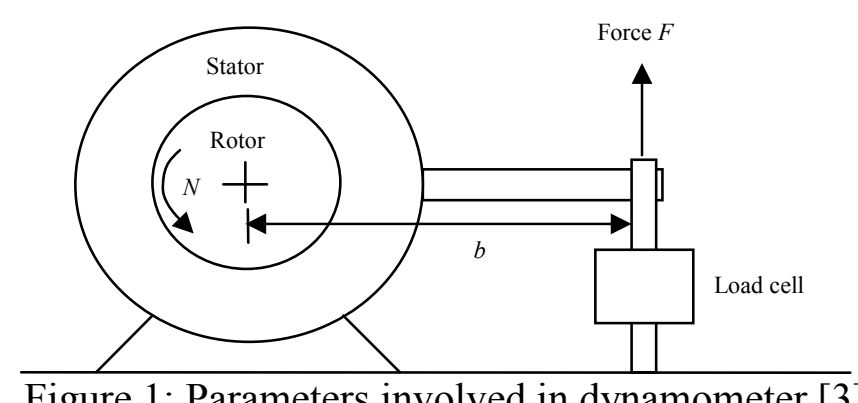

Figure 1: Parameters involved in dynamometer [3]

\section{Specific fuel consumption}

The parameter that indicates how good the engine performance is $s f c$. The lower $s f c$ means the better the engine. This parameter is expressed in term of specific fuel consumption in kilograms of fuel per kilowatt-hour. There are two types of $s f c ; b s f$ and $i s f c[2,4] . B s f c$ and isfc are the specific fuel consumptions base on $b p$ and $i p$ respectively.

$$
s f c=\frac{\text { Fuel consumption per unit time }}{\text { Power }}
$$

\section{Mean effective pressure}

The parameter that measure the work done per unit displacement volume is mep [2]. It increases as manifold pressure increases. There are two important parameters for mep; imep and bmep. The imep is the net work per unit displacement volume done by the gas during compression and expansion. It may be considered to consist of fmep and bmep as shown in Eq. 9. fmep is the portion of friction losses. Meanwhile, the bmep is the external shaft work per unit volume done by the engine.

$$
\text { imep }=\text { bmep }+ \text { fmep }
$$

The mep is the average pressure that results in the same amount of indicated or brake work produced by the engine. Based on torque for four stroke engine, the bmep is shown in Eq. 10 and in term of power the bmep is shown in Eq. 11. 


$$
\begin{aligned}
& \text { bmep }=\frac{4 \pi \tau}{V_{d}} \\
& \text { bmep }=\frac{2 \dot{W}_{b}}{V_{d} N}
\end{aligned}
$$

\section{Methodology}

In this study the computer simulation method using GT Power is used. The engine specification is shown in Table 1. This engine being modeled in GT Power software is shown in Figure 2. Air with compositions of $76.7 \% \mathrm{~N}_{2}$ and $23.3 \% \mathrm{O}_{2}$ at pressure 1 bar and temperature $26.85^{\circ} \mathrm{C}$ is being modeled as env-01. The properties for env-02 are similar with env-01. The intake system consists of intrunner_airfilter (intake runner for air filter), airfilter-01 (airfilter box), intrunner-01 (intake runner) and intport-01 (intake port). These parts represent the pipes with specific parameters as shown in Table 2. The exhaust system consists of exhport-01 (exhaust port), exhrunner-01 (exhaust runner), muffler-01 (muffler) and exhrunner-exit-01 (exhaust tail). These parts also represent the pipes with specific parameters as shown in Table 3. Intvalve-01 represents intake valve and exhvalve-01 represents exhaust valve. The parameters of these valves are shown in Table 4.

Table 1: Engine specification

\begin{tabular}{cc}
\hline Item & Technical Specification \\
\hline Type & Single cylinder, vertical, air-cooled, direct injection, 4 stroke \\
Bore $(\mathrm{mm})$ & 86 \\
Stroke $(\mathrm{mm})$ & 70 \\
Displacement $(\mathrm{L})$ & 0.406 \\
Initial angle of fuel delivery $(\mathrm{CA})$ & $-22^{\circ} \pm 1^{\circ} \mathrm{BTDC}$ \\
Intake valve clearance $(\mathrm{mm})$ & $0.1 \sim 0.15$ (cold state) \\
Exhaust valve clearance $(\mathrm{mm})$ & $0.1 \sim 0.15$ (cold state) \\
Exhaust temperature $\left({ }^{\circ} \mathrm{C}\right)$ & $\leq 480$ \\
Pressure of injection $(\mathrm{MPa})$ & $\leq 19.6 \pm 0.49$ \\
Mean effective pressure $(\mathrm{kPa})$ & $561.6 @ 3000 \mathrm{rpm}, 543.5 @ 3600 \mathrm{rpm}$ \\
Consumption rate of fuel $(\mathrm{g} / \mathrm{kW})$ & $\leq 273.5 @ 3000 \mathrm{rpm}, \leq 285.7 @ 3600 \mathrm{rpm}$ \\
\hline
\end{tabular}

Table 2: Parameters for intake system

\begin{tabular}{ccccc}
\hline & Intrunner_airfilter & Airfilter-01 & Intrunner-01 & Intport-01 \\
\hline Diameter at inlet end $(\mathrm{mm})$ & 44.88 & 159.632 & 40.44 & 40.6973 \\
Diameter at outlet end $(\mathrm{mm})$ & 62.13 & 159.632 & 40.1 & 32.78 \\
Length $(\mathrm{mm})$ & 80 & 69.64 & 59.7 & 55.2 \\
Discreatization length $(\mathrm{mm})$ & 34.4 & 34.4 & 34.4 & 34.4 \\
Wall temperature $\left({ }^{\circ} \mathrm{C}\right)$ & 28.85 & 28.85 & 76.85 & 176.85 \\
\hline
\end{tabular}

Table 3: Parameters for exhaust system

\begin{tabular}{ccccc}
\hline & exhport-01 & exhrunner-01 & muffler-01 & exhrunner-exit-01 \\
\hline Diameter at inlet end (mm) & 26.38 & 27.86 & 138.88 & 34.6 \\
Diameter at outlet end (mm) & 29.82 & 27.86 & 138.88 & 34.6 \\
Length (mm) & 40.4 & 98 & 283.4 & 25.6 \\
Discreatization length (mm) & 47.3 & 47.3 & 47.3 & 47.3 \\
Wall temperature $\left({ }^{\circ} \mathrm{C}\right)$ & 480 & 480 & 480 & 480 \\
\hline
\end{tabular}




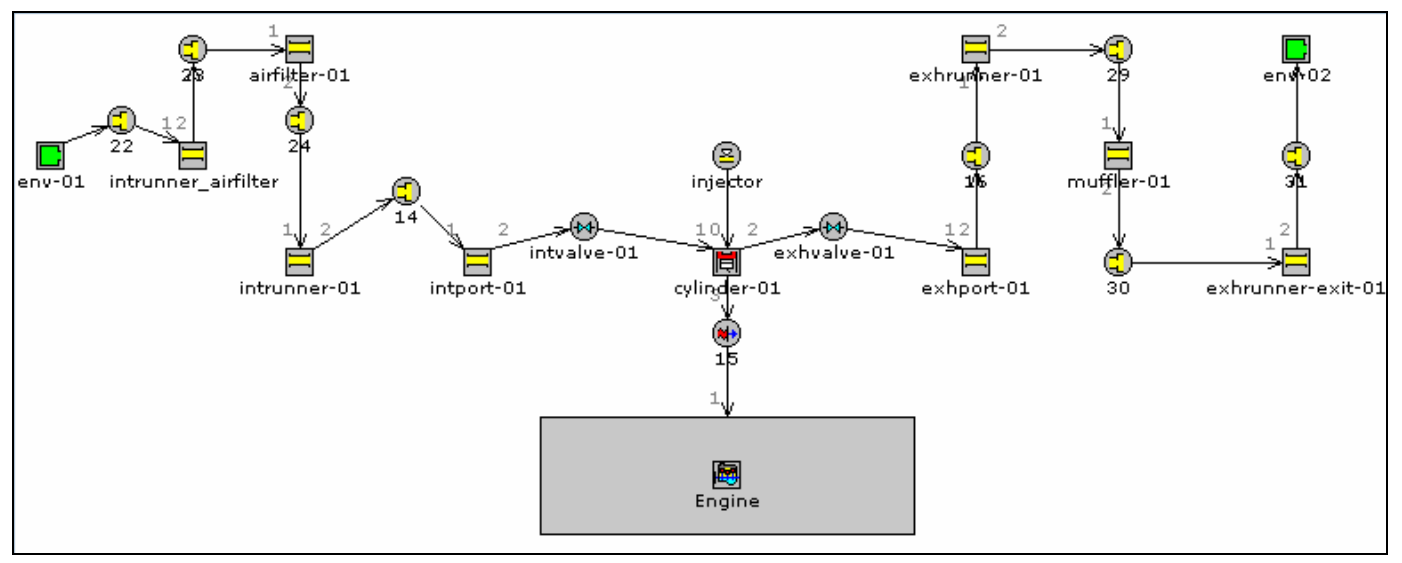

Figure 2: Engine modeling using GT Power software

Table 4: Parameters for intake and exhaust valves

\begin{tabular}{ccc}
\hline & Intvalve-01 & Exhvalve-01 \\
\hline Valve diameter $(\mathrm{mm})$ & 35.54 & 29.04 \\
CAM timing angle $\left({ }^{\circ} \mathrm{CA}\right)$ & 462.5 & 214.6 \\
Valve lash $(\mathrm{mm})$ & 0.125 & 0.125 \\
\hline
\end{tabular}

\section{Results and discussion}

For power output, only indicated power is being discussed. This is due to data specification from engine manufacturer is not enough for calculation of brake power. Indicated power gained from simulation is plotted against rpm as shown in Fig. 3. From the graph, the indicated power value is selected at 3000 and $3600 \mathrm{rpm}$ as a comparison to theoretical value. By using the simulation software the results are $5.63 \mathrm{~kW}$ at $3000 \mathrm{rpm}$ and $6.54 \mathrm{~kW}$ at $3600 \mathrm{rpm}$, meanwhile the results by using Eq. 3 are $5.72 \mathrm{~kW}$ at $3000 \mathrm{rpm}$ and $4.93 \mathrm{~kW}$ at $3600 \mathrm{rpm}$. By comparison the results at 3000 rpm are significant.

Indicated torque by simulation is shown in Fig. 3. Similar to indicated power, the indicated torque that has been selected for comparison for indicated torque are $5.72 \mathrm{~kW}$ at $3000 \mathrm{rpm}$ and $4.93 \mathrm{~kW}$ at $3600 \mathrm{rpm}$. By referring to Eq. 6 and indicated power obtained by calculation at specific $\mathrm{rpm}$, the indicated torque theoretically can be calculated. The results are $5.63 \mathrm{~kW}$ at $3000 \mathrm{rpm}$ and $6.54 \mathrm{~kW}$ at $3600 \mathrm{rpm}$. By comparison the results at $3000 \mathrm{rpm}$ are significant.

Specific fuel consumption is one of the important parameters to be considered whether the engine is good or not. For this research, only the indicated specific fuel consumption is studied. Fig. 4 shows the indicated specific fuel consumption result for simulation. The values of result are 275.115 and $383.007 \mathrm{~g} / \mathrm{kWh}$ at 3000 and $3600 \mathrm{rpm}$ respectively. The results from engine manufacturer are 273.5 and $285.7 \mathrm{~g} / \mathrm{kWh}$ at 3000 and $3600 \mathrm{rpm}$ respectively. By comparison the results at $3000 \mathrm{rpm}$ are significant. Indicated mean effective pressures as mention by engine manufacturer are 5.616 and 5.435 bar at 3000 and $3600 \mathrm{rpm}$ respectively.

Indicated mean effective pressure result for simulation is shown in Fig. 4. From the graph, the indicated mean effective pressures are 5.632 and 4.045 bar at 3000 and 3600 rpm respectively. By comparison the results at $3000 \mathrm{rpm}$ are significant. 


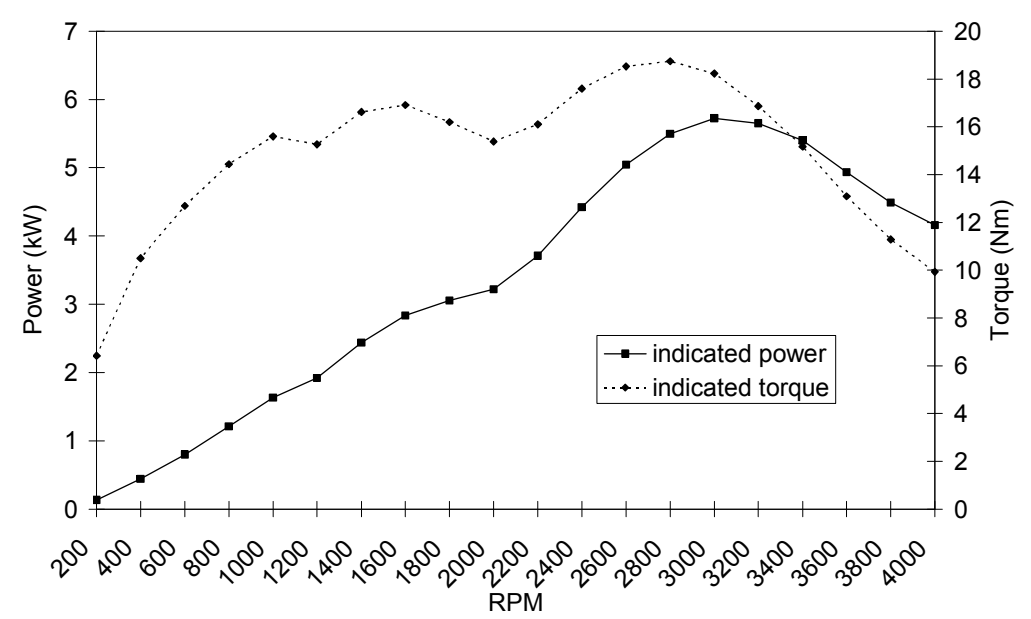

Figure 3: Indicated power and torque graph for simulation.

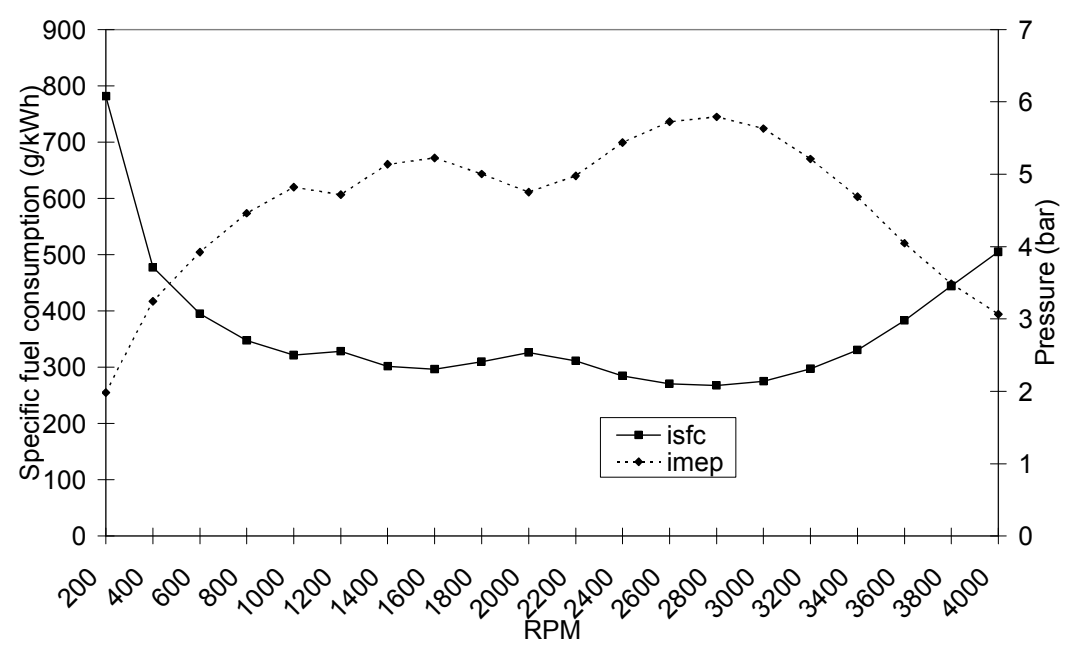

Figure 4: Indicated specific fuel consumption and mean effective pressure graph for simulation.

\section{Conclusion}

Comparison of parameters such as indicated power, indicated torque, indicated specific fuel consumption and indicated mean effective pressure have been successfully validated with the results from engine manufacturer and theoretical equation. The results at $3000 \mathrm{rpm}$ are significant compared to results at $3600 \mathrm{rpm}$. Although the results for $3600 \mathrm{rpm}$ is not significant but the trend of the graph shows the similar pattern with other researchers. For further research, experimental study will be conducted to validate the simulation results.

\section{References}

[1] U.G. Riegler and M. Bargende: Direct Coupled 1D/3D-CFD-Computation (GT-Power/StarCD) of the Flow in the Switch-Over Intake System of an 8-Cylinder SI Engine with External Exhaust Gas Recirculation (Society of Automotive Engineers Inc., 2002-01-0901, 2002).

[2] C.R. Ferguson \& A.T. Kirkpatrick: Internal Combustion Engines: Applied Thermosciences, $2^{\text {nd }}$ Ed., John Wiley \& Sons, Inc., 2001.

[3] J.B. Heywood, Internal Combustion Engine Fundamentals, McGraw-Hill, 1988.

[4] V.Ganesan, Internal Combustion Engine, $2^{\text {nd }}$ Ed., Tata McGraw-Hill, 2003. 